\title{
Exploration on the Reform of "Integration of Theory and Practice" Teaching Mode of Professional Undergraduate Curriculums-Taking the Example of Undergraduate Majors in Vehicle Engineering
}

\author{
Qing-de ZENG and Long WANG*
}

Guangxi University of Science and Technology, Liuzhou, Guangxi 545006, China

${ }^{\star}$ Corresponding author

Keywords: Vocational teachers capital division, Vehicle engineering, Core professional courses, "Integration of Theory and Practice" teaching.

\begin{abstract}
At present, the strong inertia of "subject center" of the specialized courses in undergraduate education of teachers creates the disjunction between theory and practice. It is hard to improve the teaching quality with the teacher as the classroom form with students listening as the principal manifestation. The teaching process and evaluation process Separation, leading students not to pay attention to normal learning, focusing only on examination review; this must be performed for reform. To study the teaching system of "dual-type" vocational education teachers and the main teaching methods of the core professional courses, explore the "Integration of Theory and Practice" model of the professional core courses of the professional teachers of vocational education, and adopt the principle of "combination of work and study, task-driven and action oriented" Guiding ideology so that the talent cultivation process will be comprehensively and stereoscopically constructed and a typical teaching model suitable for the cultivation of "double-qualified" teachers in vocational education will be built to improve the quality of education and teaching.

Nowadays, with the continuous expansion of the students in vocational education and the continuous improvement of the quality requirements, the teachers of vocational education are becoming more and more attention. However, due to the cultivation of the teachers' capital section mainly in the traditional undergraduate colleges, these training colleges and universities have long been cultivated: the poor effectiveness of teacher training, the teaching mode of teaching staff training, the backward teaching methods and teaching methods, the training of vocational teachers The model and the quality of training cannot meet the needs of the development of vocational education today, especially the traditional teaching modes and methods of core specialized courses, which become the bottleneck restricting the development of vocational education in our country. The specific problems in the teaching of specialized subject teachers in capital specialty are as follows:
\end{abstract}

\section{A Strong "Discipline Center" Inertia, Resulting in a Disconnect between Theory and Practice}

The inertia of the influential "subject center" of traditional undergraduate colleges has caused the disconnection between theory and practice. Often appear in the classroom of colleges and universities, "see the knowledge, not ability, see the theory, not seen in practice, only speak, do not do other phenomena's. To vehicle engineering vocational teachers, the professional is a comprehensive strong professional, which integrates mechanics, Mechanical, automatic control technology, humanities and many other aspects of knowledge, for the professional training of professional teachers has added knowledge of pedagogy, according to the "professional standards of secondary vocational school teachers," the requirements of graduates should have a technical, normal and Professional "three characteristics", and professional ability, normal ability and professional ability must be honed through practical links to enhance, therefore, the basic idea of optimization of professional courses system of vocational training of vehicle engineering teachers is: 


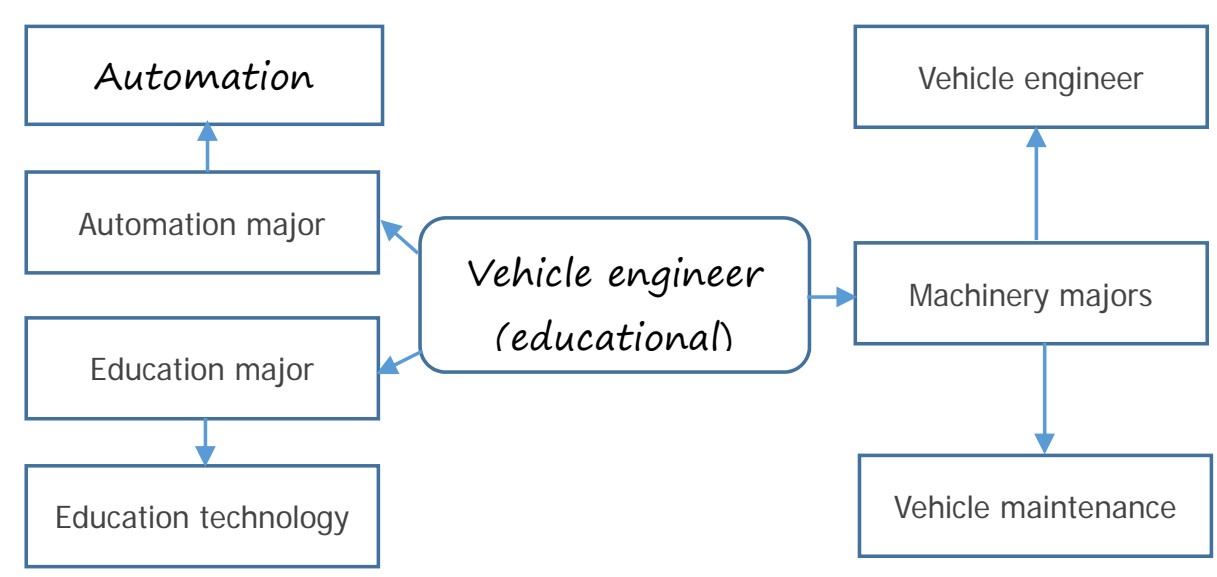

Figure 1. Vehicle Engineering Courses System

Vehicle Engineering Vocational teaching staff professional knowledge structure system:

- Constructing a teaching system with the goal of "three qualities";

- Formulation of training program centered on comprehensive quality education;

-The proportion of class hours given by "thick foundation and wide major";

-Professional, "double-type" set of professional modules must, elective course.

Course categories are divided into quality education modules, subject modules, teacher education module. The main task of professional automotive teachers and work process of the main line, set up modular and practical teacher education courses, breaking education, psychology, subject teaching method "Lao San Men" curriculum structure system; especially the professional The curriculum model should be based on the teaching method of "realism integration" course, highlighting the education and teaching skills, professional technical skills and vocational skills training of vocational teachers and students. Throughout the training process, to ensure that students have a solid professional skills and teaching skills. However, the traditional teaching methods of each module teaching modules are separated, cannot do the above-mentioned "dual-type" ability to develop requirements.

\section{The Teacher Said that Students Listen to the Main Forms of the Classroom Form, it is Difficult to Improve the Quality of Teaching}

In the domestic undergraduate colleges and universities, the teaching of the core specialized courses generally adopts the teaching method of separating the theory from the practice, that is, the theory class is first taught about a certain class hour, and the theoretical classroom manifests as the teacher "full house", the students passively accept, then it took a long time for a small amount of practical lessons to take place. In this way, because the theory and practice are artificially separated, there are several shortcomings as follows: First, the time distance between theory and practice is far, which makes the students' practical knowledge of the theory blurred and fails to make use of reality Training Consolidation theory requirements; Second, training projects and theoretical knowledge gaps. Due to the type of training equipment and economic, safety and other factors, training cannot be carried out in accordance with the theoretical focus and difficulties to carry out teaching, but mostly in accordance with training equipment and consumables to choose the operation of the project so that the focus of the profession And difficulties cannot be fully reviewed and consolidated through practical training; Third, teachers of theory and practice are not the same person, resulting in different content taught. Teaching theory is often theoretical type of teachers, and teachers are often engaged in practical training has some pragmatic ability of the teachers, both are not the same teacher often from the knowledge of students confused, in the end that one teacher is right It?

Graduates who cultivate according to this kind of cultivation method are out of line with the theory and practice, and there is a widespread phenomenon of lack of pragmatic ability. Graduates who are formed by such teachers cannot adapt to the mode of economic growth gradually from extensive to intensive, quantitative to qualitative Changing economic and social development requirements. The 
current reality of employment difficulties, school graduate's increases year after year, but the business needs the robust theory, practical ability of the lack of qualified personnel. There are two contradictory problems in the labor market in our country, such as "difficulty in finding employment" and "difficulty in recruiting for jobs." The problems are mainly manifested in that a large number of college graduates cannot locate suitable jobs, and many enterprises have specialized jobs the urgently needed skilled technicians find it difficult to recruit more students. This shows that the existing training methods of entertaining functional training in the theory of higher education system in our country are disadvantageous for the training of vocational teachers. However, the teaching of core professional courses in foreign countries generally adopts the teaching mode of "task-driven and onepractice". This training mode focuses on the mastery of practical skills oriented to specific job-posts, and greatly enhances the pragmatic ability of educators. At the same time, the original abstract theory deepens the depth of theory due to the actual hands-on operation process and logic, it will help to cultivate talented professionals in line with the needs of social progress. In particular, we should cultivate "double-qualified" teachers in vocational schools with comprehensive qualifications, solid foundation, skilled personnel and capable of instructing integrated theories and practices.

At present, the root cause of the above embarrassing situation lies in the fact that the theory and practice of classroom performance in teacher-teacher training are out of line with the teacher-teacher and student listening as the main forms of classroom performance, especially the separation of the core professional curriculum teaching theory and practice.

\section{The Separation of Teaching Process and Evaluation Process, Leading Students not to Pay Attention to Normal Learning, Focusing only on Examination Review}

Traditional teacher professional teaching more concerned about the final evaluation of the final evaluation of the development process of students in the process of little attention. Mainly in:

-Excessive reinforcement of the test scores.

- Mislead the students to focus only on the notional knowledge of memory and recitation, while ignoring the application of knowledge and practical ability to improve.

- Focus on the test scores to evaluate the ability of students.

Due to the one-sidedness of the final assessment, students have many negative effects. Eventually led to many students do not adopt notes in class, exam back someone notes, test notes, do not mind the improvement of comprehensive professional ability.

However, the training of teacher education in vocational education requires systematic knowledge and professional training to fully prepare for the future teaching career. Therefore, at this stage, we should improve the knowledge structure (including three aspects of general knowledge, disciplinary expertise, and educational expertise) of future vocational college teachers as well as train their specialized abilities and teaching abilities as key objectives. This can be done in the traditional teaching model of specialty undergraduate course.

In view of the above shortcomings in the training of professional teachers in vocational education, the national key construction of vocational teachers training base Guangxi University of Science and Technology to the Ministry of Education vehicle engineering professional point construction as an opportunity, the vehicle engineering professional undergraduate core curriculum reform Exploration, the specific practices are:

-To study the curriculum system of "dual-type" teacher education and the principal teaching methods of core professional courses.

We reconstruct the course system for the vehicle engineering major (in the direction of the instructor). While reserving the necessary general education courses and specialized basic courses, we have reformed the specialized theoretical courses and introduced the rationale for the automotive construction courses Integrated teaching mode, increase the proportion of technology application ability training, therefore, curriculum resources in the professional curriculum outline, part of the main course teaching materials need to reposition and write. In the course of reforming some main courses, the curricula should be in the nature of one course, the goal should be to strengthen the professional ability, the main content should be closely related to the cultivation of professional 
ability, and what should be done and not done; the selection of teaching contents of some specialized courses, the basic problems of the relations among the labor, technical and vocational education in the professional field should be analyzed. Teaching contents of the specialized course must change with the progress and development of technology, especially considering the new technologies that have been applied to practice the production process. In particular, it is necessary in order to study the relationship between labor and education, such as the organization and form of work, the ability of workers, and so on. Students in vocational schools must have the capacity to work in a typical vocational activity. The objective is tantamount to train qualified teachers to be capable of such training and to study how to choose the teaching content on the basis of scientific orientation. In addition, the model should be conducive to the integration of teaching and learning model.

-Exploring the teaching mode of "professional and practical" in the specialized subject teaching of the professional teachers in vocational schools, adopting the guiding ideology of "combination of work and study, task-driven and action oriented" to lay the foundation for the construction of the teaching mode of undergraduate specialized core curriculum. Constructing a Typical Teaching Method Suitable for Training "Double Teachers" in Vocational Education to Improve the Teaching Quality of Education.

-On-the-job training of teachers and specialties in professional core courses Exploration of the implementation of "Integration of Theory and Practice" teaching methods, namely integration of vehicle engineering core professional courses theory and training courses, reconstruction of teaching content, mining vehicle engineering professional core courses In theoretical knowledge and practice training integrated knowledge entry point, in accordance with the "information $\rightarrow$ decision-making $\rightarrow$ plan $\rightarrow$ implementation $\rightarrow$ inspection $\rightarrow$ assessment" of the work order, from theory to practice training, the talent cultivation process of all-round, three-dimensional.

-Through the research and research, combined with the practical and practical requirements of the theory and practice, especially the practical talents must have the ability to analyze and solve the car failure, to develop more ideal assessment methods, such as: the usual results, theory Achievements and practical performance of the three components of the evaluation mechanism. To overcome the contemporary assessment of the "high score low energy", the form is more important than the actual advantages and disadvantages.

In short, according to the status qua of vocational education, the national standard of secondary vocational teachers, "double teacher" training law for the construction of the training model to carry out training objectives and specifications, training program design, curriculum, training methods, especially the professional core curriculum teaching Method research and practice. That is, according to the requirement of "academic, teacher training, and professional" training of vocational teachers, vocational education concept and beneficial practices should be introduced into general undergraduate education, combined with the actual training of vocational teachers in four- Select the vehicle engineering specialty, carry out job occupational ability analysis, explore the job-oriented curriculum system construction, formulate talent training programs, design and cultivate process models, and implement the "realistic and integrated" teaching methods in the core specialized courses. We have achieved the following results:

-To establish a team of teachers who have the concept of "integration of realistic education and practical teaching";

-Establish or reform a batch of teaching facilities and facilities that are adapted to the teaching of "realism and one teaching";

-Teaching management on the core professional courses to form a "Integration of Theory and Practice" course model.

\section{Acknowledgement}

This article comes from the project of "Reform and Practice of Integration of Theory and Practice" (2017JGA231) undergraduate course reform for higher education in Guangxi in 2017. 


\section{References}

[1] Liu Xiaojun, Yang Xiaohua. Higher Vocational "Automobile Engine Structure and Maintenance" course break through teaching practice exploration [J]. Car Maintenance and Repair, 2017 (18): 43-44.

[2] ZHOU Bao-chun. Design and Implementation of Practical and Integrated Teaching of Automobile Operation and Maintenance Technology Courses [J] .Automotive and Driving Maintenance (Revised Edition), 2017 (12): 108.

[3] ZHANG Xin-ran, SHI Quan-hao, LI Xiuling. Exploration and research on the real-world integrated teaching of chassis structure and maintenance [J] .Car Service \& Maintenance, 2017 (12): 102.

[4] Ren-ting.A discussion on the integration of teaching and learning in automotive electronics and electronics [J] .Automotive and Driving Maintenance (Revised Edition), 2017 (12): 109.

[5] Cui Jianping. The Construction of Practical Teaching System of Ideology and Politics Integration in Higher Vocational Colleges [J]. Education and Careers, 2015 (36): 118-120.

[6] Song Zhao. Practice and thinking of some problems in the integration of higher vocational education and practical teaching [J]. China Vocational and Technical Education, 2014 (35): 54-56.

[7] KE Yan-lin. Research on the Teaching Quality Evaluation Index System of the Integrative Classroom [J] .Jiangjiao Jiaotong Vocational College, 2013, 15 (03): 35-39.

[8] Zhao Chunjiang, Guan Yuqin, Yan Xiaohong. Practice and analysis of integrated teaching practice [J]. Adult Education, 2012, 32 (12): 61-63.

[9] Xu Jian.Study on the Realistic Teaching Design of Vocational School [J]. Contemporary Vocational Education, 2012 (01): 36-39.

[10] Zhang Yangqun, Deng Zemin. Study on the Design and Compilation of Practical Teaching Material in Vocational Education [J]. Chinese Vocational and Technical Education, 2011 (24): 6872 .

[11] Xie Wenming. Probing into the Realistic Integration Teaching Mode under the Cooperation Mechanism between School and Enterprise [J]. Vocational and Technical Education, 2011, 32 (17): 34-36.

[12] WANG Fang. Analysis of Teaching Effect of "Realistic Integration" of Automobile Major [J]. Journal of Beijing Agricultural Vocational College, 2010, 24 (06): 67-70.

[13] Li Juan. "Realistic integration" of laboratory research and exploration [J]. China Adult Education, 2010 (12): 35-36.

[14] Liu Ping, Zhou Guansheng, Ruan Jun, Li Yin. Study on the Evaluation System of "Realistic Integration" in Higher Vocational Education [J]. Vocational and Technical Education, 2009, 30 (26): $65-66+71$.

[15] Chen Bing. Practice and application of the integrated teaching of li-li in numerical control [J]. Vocational Education Forum, 2007 (06): 16-20. 